\title{
LAS CIUDADES AUTÓNOMAS DE CEUTA Y MELILLA Y EL CONFLICTO EN DEFENSA DE LA AUTONOMÍA LOCAL. (COMENTARIO A LA SENTENCIA 240/2006, DE 20 DE JULIO)
}

\author{
POR \\ JOSÉ MARÍA PORRAS RAMÍREZ \\ Profesor Titular de Derecho Constitucional \\ Universidad de Granada
}

\section{INTRODUCCIÓN}

De entre todas las iniciativas llevadas a cabo en desarrollo del llamado "Pacto local", suscrito por el Gobierno de la Nación y la Federación Española de Municipios y Provincias, a fin de colmar las carencias de todo orden que afectan al régimen jurídico de la autonomía local en España, la más notable de todas ellas fue, sin duda, la que llevó a promover, en 1999, la modificación de la Ley Orgánica del Tribunal Constitucional. El propósito no era otro que atribuir a los gobiernos locales un medio reaccional extraordinario que permitiera su acceso directo a aquél, en aras de lograr la tutela plena y efectiva de su autogobierno y autoadministración característicos. De ese modo, se pretendía subsanar el carácter, generalmente considerado, incompleto e insuficiente de la protección brindada a la autonomía de referencia, dada la potencial vulnerabilidad a la que, habitualmente, se ve sometida la misma por la ac- 
ción del legislador, tanto estatal como, sobre todo, autonómico. A ese fin, desechando otras alternativas, al acoger el Dictamen del Consejo de Estado, el legislador optó por crear, de acuerdo con las previsiones expresivas de una competencia de atribución contenidas en el art. $161 \mathrm{~d}$ ) $\mathrm{CE}$, un nuevo procedimiento denominado "conflicto en defensa de la autonomía local» (art. 59.2 LOTC), que pasó a regularse en el nuevo Capítulo IV del Título IV de la indicada Ley Orgánica ${ }^{1}$.

Se perfiló así un singular "conflicto de competencia legislativa", mediante el cual, a instancias de los gobiernos locales legitimados, se permite a los mismos solicitar, de modo directo e inmediato, un pronunciamiento del Tribunal Constitucional acerca de si se ha producido, por la acción de una ley estatal o autonómica, menoscabo alguno de la autonomía que les garantiza la Constitución. Tras ello, de considerarlo oportuno el Pleno del propio Tribunal conocedor de la demanda, cabe iniciar un nuevo procedimiento, disociado artificialmente del anterior, para controlar la validez de la ley originaria de la controversia.

Dicha fórmula, rebuscada y un tanto confusa, al venir a mezclar procedimientos ya existentes, no trata sino de obviar o vencer, de forma oblicua, la imposibilidad de extender a los gobiernos locales la legitimación activa en el recurso de inconstitucionalidad. La misma viene así a permitir a aquéllos que cumplan los rigurosos criterios selectivos establecidos, dispuestos con una vocación claramente disuasoria ${ }^{2}$, proceder a la impugnación de una ley ante la jurisdicción constitucional, instando así la salvaguardia y eventual restitución de la imagen social

1 Acerca del proceso constitucional de referencia, cfr., entre otros, J. JIMÉNEZ CAMPO, «Notas sobre la protección de la autonomía local frente al legislador en el Derecho español», en Revista Española de Derecho Constitucional, n. ${ }^{\circ}$ 53, 1998, pp. 3356; M. Pulido QueCEDO, "La reforma de la Ley Orgánica del Tribunal Constitucional: el conflicto en defensa de la autonomía local», Pamplona, Aranzadi, 1999; J. M. ${ }^{\text {a PoRRAS }}$ RAMíREZ, "El conflicto en defensa de la autonomía local ante el Tribunal Constitucional», Madrid, Civitas, 2001; R. NARANJO DE LA CRUZ, "El proceso constitucional para la protección de la autonomía local en España y Alemania», Madrid, INAP, 2003; y M. ${ }^{a}$ D. CABELlos FERNÁNDEZ, "El conflicto en defensa de la autonomía local», Madrid, Civitas, 2003.

2 Cfr., el ATC 418/2003, de 16 de diciembre, por el que se acuerda inadmitir a trámite el conflicto planteado, inicialmente, por 1185 municipios contra la Ley 18/2001, de 12 de diciembre, de estabilidad presupuestaria. La inadmisión se debió al incumplimiento sobrevenido de los rigurosos requisitos de legitimación legalmente previstos, circunstancia ésta que impidió reunir el número de municipios requerido, conforme a la exigencia legal de que alcanzaran un séptimo de los existentes en el ámbito territorial de aplicación de la ley, representando, como mínimo, a un sexto de la población oficial del ámbito territorial correspondiente (art. 75, ter. 1 LOTC). 
que proyectan los mismos. Cuestión bien distinta es la que lleva a reparar en los evidentes defectos de que adolece su regulación, los cuales, como se tendrá ocasión de comprobar en el curso del comentario a la Sentencia 240/2006, subrayan la incoherencia del legislador que introdujo este procedimiento, al testimoniar su falta de visión de conjunto del modelo vigente de justicia constitucional.

En cualquier caso, debe advertirse que la Sentencia de referencia posee un carácter ciertamente extraordinario en lo que se refiere a la resolución de este tipo de conflictos. De ahí que no pueda considerársela ejemplar, en tanto que constitutiva de un auténtico "leading case» en la materia. La razón está en que el promotor de la demanda no es un gobierno local al uso, es decir, un municipio o provincia, integrado en un colectivo o destinatario único de la norma (art. 75, ter 1. LOTC), sino la Ciudad Autónoma de Ceuta, que accede a esta vía litigiosa como si de un ente local más se tratara. No en vano, la misma se ve forzada a ello al haber inadmitido, previamente, el Tribunal Constitucional, mediante Auto (ATC 202/2000), "por falta de legitimación», ex arts. 162.1 a) y 32.2 LOTC, el recurso de inconstitucionalidad que, con un mismo objeto, había promovido el Pleno de su Asamblea contra una decisión legislativa de origen estatal que, a su juicio, incide, abierta y negativamente, en la determinación del alcance de una de las más sobresalientes competencias que su Estatuto de Autonomía le atribuye.

En consecuencia, la Sentencia afronta, en este supuesto, si bien entiendo que con desigual acierto, tres cuestiones fundamentales. La primera afecta a la conformación y el desarrollo del Estado autonómico, al tiempo que permite esclarecer una de las dudas que, ante la ausencia de referencias por parte del legislador, guarda relación con la legitimación subjetiva que faculta para plantear el conflicto en defensa de la autonomía local. La misma es aquélla que lleva a establecer la vía a través de la cual las Ciudades Autónomas de Ceuta y Melilla pueden acceder directamente a la jurisdicción constitucional en defensa, frente a leyes, de su autonomía garantizada, tanto por la Constitución, como, muy especialmente, por sus respectivos Estatutos de Autonomía. La segunda cuestión alude, habida cuenta del silencio del legislador, a la necesidad de determinar el parámetro de control que el Tribunal Constitucional habrá de emplear para resolver esta modalidad de conflictos. $Y$ en tercer y último lugar, en atención al caso concreto, se valora la proporcionalidad de la actuación legislativa del Estado, a efectos de comprobar si ésta resulta legítima constitucionalmente, o si, por el contrario, carece de toda justificación, redundando, en tal caso, en una afectación lesiva de la autonomía garantizada al ente territorial de referencia. 
El presupuesto de todo ello radica en la modificación efectuada en la Disposición Adicional Tercera de la Ley 6/1998, de 13 de abril, de régimen del suelo y valoraciones, por el art. 68 de la Ley 55/1999, de 29 de diciembre, de medidas fiscales, administrativas y de orden social. Dicha reforma legislativa, impugnada ante el Tribunal Constitucional por la Ciudad Autónoma de Ceuta, permite al Estado, con respecto a aquéIla y a Melilla, tanto asumir la aprobación definitiva del Plan General de Ordenación Urbana que elaboren, y de sus revisiones o modificaciones; como, además, aportar su informe preceptivo y vinculante con anterioridad a la aprobación de los Planes Parciales, y de sus modificaciones o revisiones. En consecuencia, una medida tal afecta necesariamente a las posibilidades de ejercicio de la competencia que, en materia de "ordenación del territorio, urbanismo y vivienda", poseen ambas Ciudades Autónomas, en virtud de lo dispuesto, respectivamente, en su correspondiente Estatuto de Autonomía (art. 21.1.1. ${ }^{a}$ EAC y EAM). Por eso, antes de proceder al comentario, propiamente dicho, de la Sentencia, ha de esclarecerse cuál es la posición que ocupan Ceuta y Melilla en la organización territorial del Estado.

\section{LA PECULIAR POSICIÓN QUE OCUPAN LAS CIUDADES AUTÓNOMAS EN LA ORGANIZACIÓN TERRITORIAL DEL ESTADO}

El lugar que corresponde a las Ciudades Autónomas en el modelo de Estado compuesto que prefigura la Constitución, deriva, necesariamente, de lo dispuesto en sus respectivos Estatutos de Autonomía. Éstos se elaboraron por acuerdo de las Cortes Generales, sin contar con la intervención directa de unos territorios que no se encontraban integrados en provincia alguna, alegándose lo dispuesto en el art. 144 b) $\mathrm{CE}$, esto es, por motivos de interés nacional. Las Leyes Orgánicas $1 / 1995$ y 2/1995, de 13 de marzo, culminaron, de ese modo, la organización territorial del Estado, al aprobar dos normas estatutarias, esencialmente idénticas, que dieron lugar a la creación de dos entes territoriales, los cuales, si bien en ningún momento fueron considerados, formalmente, Comunidades Autónomas, lo cierto es que asumieron algunos de los rasgos característicos que singularizan a aquéllas, al tiempo que se les privó de otros, no menos relevantes ${ }^{3}$.

${ }^{3}$ A. X. López MiRA, "Ceuta y Melilla, ¿Comunidades Autónomas o peculiares Entes locales?», en Revista de Derecho Político, n. ${ }^{\circ} 43$, 1997, pp. 147-156. P. REQUEJO ROdríguez, "Ceuta y Melilla, ¿Ciudades con Estatutos de Autonomía o con Estatutos de heteroorganización?», en Revista de Estudios de Administración Local y Autonómica, n. ${ }^{\circ} 277,1998$, pp. 55-70. 
Resulta así que tales Estatutos, dado su carácter atípico o singular, difieren cualitativamente de sus homónimos. De ahí que los mismos no se vean acompañados de la garantía fundamental que resulta inherente a toda norma institucional básica de una Comunidad Autónoma: la que asegura su inmodificabilidad unilateral por parte del legislador estatal ${ }^{4}$. No en vano, los Estatutos de Ceuta y Melilla pueden ser reformados sin requerir el concurso del territorio afectado, esto es, bastando con la iniciativa de las Cortes Generales y del Gobierno que, aún así, habrán de seguir, a esos efectos, el procedimiento establecido en tales normas (art. 41). Si a eso se une el hecho de no establecer habilitación alguna para el ejercicio de la potestad legislativa, cabe concluir afirmando que dichos entes territoriales carecen de la garantía constitucional de la autonomía que se predica de las nacionalidades y regiones.

No obstante, pese a esas insuficiencias, no deja de ser menos cierto, también, que los Estatutos de ambas Ciudades Autónomas satisfacen las exigencias que, con carácter mínimo, contempla el art. 147.2 CE. Así, además de denominar y delimitar el territorio y organizar sus instituciones propias, tales normas determinan las competencias que asumen dichos entes territoriales dentro del marco establecido por la Constitución. Esas competencias son el resultado de yuxtaponer las atribuciones que son inherentes a un gobierno local, entendiendo por tales las que resultan de sumar las que posee un ayuntamiento y una diputación provincial (art. 25), con buena parte de las que son características de una Comunidad Autónoma (art. 21). De ello resulta la conformación de unos entes territoriales ciertamente singulares, que, a pesar de sus diferencias estructurales, vienen a completar, según se indica en los respectivos preámbulos estatutarios, la organización territorial del Estado. De ahí que su existencia afecte inevitablemente al desarrollo del mismo ${ }^{5}$.

Dichos Estatutos incluyen un amplio listado de materias sobre las que ambas Ciudades Autónomas podrán ejercer sus competencias. Dada la tardía elaboración de ambas "normas institucionales básicas", las competencias asumidas por las mismas, además de recaer sobre todas las materias que la Constitución menciona en su art. $148.1 \mathrm{CE}$, lo

${ }^{4}$ F. Balaguer Callejón, «Fuentes del Derecho», Vol. II: "Organización general del Estado y ordenamientos autonómicos», Madrid, Tecnos, 1992, pp. 132-133

${ }^{5}$ F. Balaguer Callejón, "Naturaleza jurídica del Estatuto de Autonomía de la Ciudad Autónoma de Melilla», en M. a J. Fernández Pavés (dir.), "Estatutos de Autonomía y régimen fiscal de Melilla», Barcelona. Cedecs, 1998, pp. 53-65. 
hacen, también, sobre algunas de aquéllas que la LO 9/1992 tuvo a bien transferir a las Comunidades Autónomas de régimen común, las cuales se acabaron incorporando a sus Estatutos, en virtud de las reformas efectuadas, posteriormente, en aquéllos. Cuestión bien distinta es la que lleva a reparar en las más limitadas facultades que, en comparación con las que se atribuyen a dichas Comunidades Autónomas, se permite ejercer a Ceuta y Melilla en relación con tales materias. Así, el ya mencionado art. 21 de sus Estatutos contempla un listado de aquéllas sobre las que las mencionadas Ciudades Autónomas poseen facultades consistentes en la "administración, inspección y sanción, y en los términos que establezca la legislación del Estado, el ejercicio de la potestad normativa reglamentaria». A su vez, por su parte, el art. 22 de los respectivos Estatutos enumera las materias con respecto a las cuales dichas Ciudades Autónomas poseen, igualmente, facultades ejecutivas de la legislación estatal, pudiendo así ejercer, más limitadamente, "la potestad normativa reglamentaria para la organización de los correspondientes servicios".

En consecuencia, la distinción fundamental que, en materia competencial, media entre las Ciudades y las Comunidades Autónomas, más que radicar en la mayor o menor amplitud de las materias sobre las que se asignan competencias a los respectivos entes territoriales, estriba en las facultades, de, en principio, muy desigual alcance, que, a unas y a otras, se les permite desarrollar. $Y$ es que al no habérseles asignado la potestad legislativa, Ceuta y Melilla sólo pueden ejercer una potestad reglamentaria que, en ocasiones, tendrá una proyección «ad extra», en el marco previamente determinado por la legislación del Estado (art. 21.2); mientras que, en otros casos, únicamente, repercutirá "ad intra", contrayéndose al dictado de normas estatutarias de autoorganización (art. 22.2). Aún así, en ambas situaciones, reforzando con ello su legitimidad democrática, será, en todo caso, a la Asamblea, que no al Consejo de Gobierno, a quien corresponderá el ejercicio de tales potestades normativas (art. 12.1 a)).

Queda, pues, al criterio discrecional del legislador estatal la definición del alcance del autogobierno de que gozan las Ciudades Autónomas sobre las materias de su competencia, el cual, a tenor de lo dispuesto en sus Estatutos, implica, en cualquier caso, el necesario señalamiento de un contenido mínimo que se sustrae a su libertad de disposición. De todas formas, semejante sistema de ordenación conlleva que el legislador estatal será quien apodere o desapodere a Ceuta y Melilla, ya sea regulando por sí mismo lo más relevante de la materia en cuestión, hasta el punto de llegar a comprimir, en buena medida, el margen de actuación normativa con que cuentan dichas 
Ciudades Autónomas; ya habilitándolas ampliamente para que sean ellas quienes, por sí mismas, de acuerdo con su libre criterio, efectúen el grueso de la regulación, dentro del marco genérico fijado. De la actitud del legislador estatal dependerá, por tanto, que aquéllas puedan desarrollar, efectivamente, su autogobierno, constituyendo así un ordenamiento autonómico propio; o bien, por el contrario, hayan de limitarse al desarrollo de competencias residuales, genéricamente reconducibles a tareas de ejecución administrativa, más propias de un gobierno local que de una Comunidad Autónoma.

De optar por la segunda de las alternativas que se le presentan, el legislador generará, mediante sus intensas intervenciones singulares, referidas exclusivamente a ciertos territorios del Estado, como son las Ciudades de Ceuta y Melilla, pero, en frecuentes ocasiones, con una vocación encubierta de aplicación supletoria para el resto de la Nación, disfunciones importantes en el desenvolvimiento armónico y equilibrado del Estado autonómico ${ }^{6}$. Tal hecho justifica que, en tanto en cuanto no se proceda a una reforma estatutaria que suscite la plena equiparación de aquéllas a las Comunidades Autónomas, lo que implica, necesariamente dotarlas de una potestad legislativa propia, se postule una autolimitación de la actuación normativa del Estado a los casos en que la misma resulta jurídicamente ineludible. La intención no es otra que hacer posible que sean los propios entes territoriales de referencia quienes, de no mediar una reserva de ley, puedan desplegar, plenamente, su capacidad normativa propia, con trascendencia externa, en ejercicio de su autonomía política. Y es que sólo si dicha facultad puede desenvolverse disponiendo de una amplia libertad de configuración, ambas Ciudades Autónomas tendrán la posibilidad de desarrollar las potencialidades de su autogobierno, paliando así, siquiera sea materialmente, la carencia de potestad legislativa que les afecta ${ }^{7}$.

\section{EL ACCESO DIRECTO DE LAS CIUDADES AUTÓNOMAS AL TRIBUNAL CONSTITUCIONAL}

Ese llamamiento a la realización de una interpretación integradora, "tendente a la simetría», de los principales rasgos diferenciadores que

6 F. Balaguer Callejón, "Las relaciones entre el ordenamiento estatal y los ordenamientos autonómicos. Una reflexión a la luz de la regla de la supletoriedad", en Revista Derecho Político, n. ${ }^{\circ} 44,1998$, pp. 285-305; en especial, pp. 302 y ss.

7 J. A. Montilla Martos, "La asimetría de las Ciudades Autónomas", en Revista Española de Derecho Constitucional, n. ${ }^{\circ}$ 57, 1999, pp. 65-86; en especial, pp. 81 y ss. 
asisten, a día de hoy, a Ceuta y Melilla, en aras de contribuir a un funcionamiento más coherente del Estado autonómico, no sólo guarda relación con el ejercicio de su potestad normativa, en desarrollo de sus competencias, sino que, entre otros aspectos relevantes, se vincula, también, destacadamente, a la legitimación que se atribuye a ambas Ciudades Autónomas para proceder a la impugnación de leyes que, a su juicio, generan un menoscabo de su autonomía. Sorprende así que no se haya hecho referencia expresa alguna, con ocasión de la reforma de la Ley Orgánica del Tribunal Constitucional, a las singularidades que concurren en tales Ciudades Autónomas, las cuales derivan de sus respectivos Estatutos de Autonomía. Gracias a éstos Ceuta y MeliIla cuentan, según se ha indicado, con un conjunto de competencias, de naturaleza genuinamente autonómica, que propician una modalidad de autogobierno, cuando menos en potencia, susceptible de llegar a asimilarse a aquél que disfrutan las nacionalidades y regiones; el cual viene a añadirse al haz de competencias que les permiten, al tiempo, atender las necesidades y aspiraciones de sus respectivas comunidades vecinales.

De ahí resulta la paradoja de hallarse estas Ciudades Autónomas entre las principales beneficiarias del nuevo proceso constitucional de referencia, el cual les faculta para recurrir normas con rango de ley, de procedencia inevitablemente estatal, en los supuestos en que las mismas consideren afectado lesivamente su círculo de intereses locales. Pero al tiempo que esto ocurre, se las deja inermes a la hora de impetrar, frente a la acción de leyes estatales, la defensa, acorde con su naturaleza, de las competencias con que cuentan dotadas de trascendencia claramente autonómica ${ }^{8}$. Ninguno de estos distingos efectúa, empero, el Tribunal Constitucional, que insiste en reputar a Ceuta y Melilla, a efectos, tanto sustantivos como procesales, meros entes locales (AATC 320/1995, 10/1996 202/2000 y STC 240/2006), no reparando en la distinta naturaleza, ya local, ya autonómica, de las competencias de que son titulares ambas Ciudades Autónomas. Esa reducción de su estatus devalúa su posición constitucional, negando sentido alguno a la particular configuración estatutaria que ambas han recibido, la cual no pretende sino propiciar, siquiera sea de manera peculiar y atípica, su inserción en el Estado autonómico, completando así la organización territorial del mismo.

En consecuencia, habida cuenta de la imprevisión del legislador, probablemente, lo más adecuado sería que el Tribunal Constitucional

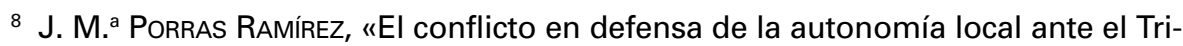
bunal Constitucional», op. cit., pp. 89-91. 
introdujera una nueva orientación en su jurisprudencia, a efectos de reevaluar la consideración que le merecen tales Ciudades Autónomas. Optar por tutelar constitucionalmente la autonomía de que gozan las mismas, como si ésta tuviera, exclusiva y uniformemente, una consideración tan solo local, debiendo, por tanto, articularse su amparo directo frente a leyes, a través del conflicto en defensa de la autonomía local, desmerece su posición, intensificando así los rasgos asimétricos que presenta la organización territorial del Estado. De ahí que, quizá, lo idóneo sea reconocerle a Ceuta y Melilla legitimación activa para plantear recursos de inconstitucionalidad, en los supuestos en que sus competencias de naturaleza autonómica, garantizadas estatutariamente, se vean, con manifiesta desproporción, vaciadas de todo contenido por la acción del legislador estatal. Una interpretación del art. 32.2 LOTC que extienda a los órganos colegiados ejecutivos y a las asambleas de Ceuta y Melilla la legitimación con la que ya cuentan, a esos efectos, las instituciones homónimas de las Comunidades Autónomas, conduciría derechamente a ello, sin necesidad de operar cambio legislativo alguno.

En este sentido, resulta sumamente elocuente el hecho de que la LO 7/1999, introductoria del nuevo procedimiento, no haga mención alguna a ambas Ciudades Autónomas, a efectos de conferirles expresamente legitimación activa en el conflicto en defensa de la autonomía local. Ello contrasta, abiertamente, con las referencias que se hacen a otros "sujetos especiales", como son las Islas, Cabildos, Consejos Insulares, Juntas Generales y Diputaciones Forales, que, en tanto que titulares de regímenes locales singulares, merecen alusiones específicas en las Disposiciones Adicionales Tercera y Cuarta de la Ley Orgánica del Tribunal Constitucional. Semejante silencio acerca de Ceuta y MeliIla no parece que exprese, cuando menos en este caso, un olvido del legislador, sino una decisión consciente del mismo, sabedor de que ambas Ciudades Autónomas desbordan la condición de gobiernos locales, dada su inserción, por vía estatutaria, en el Estado autonómico, como piezas integrantes del mismo.

Aún así, el supremo intérprete de la Norma Fundamental, fiel a su jurisprudencia, ha cerrado las puertas, siquiera por ahora, a ese reconocimiento, al reiterar, en el Fundamento Jurídico Cuarto de su Sentencia, que Ceuta (como Melilla) no es más que un ente local, que no una Comunidad Autónoma. De ahí que haya considerado que la misma sólo puede recurrir directamente las leyes que entiende que afectan negativamente a su círculo de intereses, acudiendo al único procedimiento que le permite el acceso inmediato a la justicia constitucional, esto es, al conflicto en defensa de la autonomía local. De ese modo, el 
Tribunal Constitucional ha hecho caso omiso a las referencias que se contienen, tanto en el Preámbulo, como en el articulado de su Estatuto, las cuales vienen a indicar que "Ceuta (léase, indistintamente, Melilla) accede a su régimen de autogobierno, gozando de autonomía para la gestión de sus intereses, integrándose y completando el sistema autonómico que se ha desarrollado a partir de la Constitución española» (Preámbulo y art. 1); o a aquellas otras que, en desarrollo de esa declaración de principio, llevan a dicha norma institucional básica a establecer la denominación (art.1) y delimitación de su territorio (art. 2); su bandera, escudo e himno (art. 3); los principios u objetivos a que se orienta su autogobierno (art. 5); el nombre asignado a sus órganos institucionales, los cuales resultan idénticos a los que se atribuyen a aquéllos con que se dota a las Comunidades Autónomas (art. 6); la nueva estructura organizativa que asume, la cual viene a superponerse a la municipal, ya existente (arts. 7 a 19); o el listado de competencias, genuinamente autonómicas, con que cuenta dicha Ciudad, las cuales traen causa de los arts. 148 y 149 CE (arts. 21 y 22), añadiéndose, novedosamente, a aquéllas con que dicho ente territorial ya contaba, en su condición previa de gobierno local, que sigue manteniendo (art. 25).

Ciertamente, el Tribunal Constitucional es consciente, como pone de manifiesto en el Fundamento Jurídico Séptimo de su Sentencia, de la brecha que se abriría en el sistema de justicia constitucional si Ceuta y Melilla no pudieran instar la tutela directa de todas sus competencias, en los supuestos en que crean afectada alguna de las mismas, de resultas de la acción de una ley estatal. Por eso, aun reconociendo que la autonomía de la ciudad de Ceuta es "diferente de aquélla de la que disponen los municipios que se rigen por la legislación estatal», al disponer «de un régimen especial de autonomía basado en el procedimiento previsto en el art. 144 b) CE», señala que éste no es más que "un régimen singular de autonomía local», que el legislador determina en virtud de la "garantía plural de las autonomías municipal y provincial» contemplada en los arts. 137, 140 y $141 \mathrm{CE}$, lo que lo habilita para determinar "las facultades de carácter especial que puedan venir atribuidas a algunos entes locales en virtud de circunstancias que tengan reflejo en su régimen jurídico». De ahí que, reiterando que Ceuta carece de legitimación activa en el recurso de inconstitucionalidad, al no ser una Comunidad Autónoma, e insistiendo en que todas sus competencias son propias de un gobierno local, el Tribunal Constitucional aproveche la reforma introducida en su Ley Orgánica reguladora para considerar a la totalidad de las mismas, sin distinción cualitativa alguna, amparables directamente, frente a leyes, a través de la nueva vía de ac- 
ceso a su jurisdicción que entraña el conflicto en defensa de la autonomía local.

Por las razones ya indicadas, las cuales se fundamentan, tanto en su Estatuto, como en los deseos de alcanzar un más equilibrado y armónico funcionamiento del Estado autonómico, no comparto esta concepción reduccionista del estatus que asiste a ambas Ciudades Autónomas. Entiendo así, más bien, coincidiendo con lo expresado por el Abogado del Estado, que el peculiar régimen competencial que posee Ceuta no está amparado, a través de dicho procedimiento, en lo que aquél excede de la autonomía local constitucionalmente garantizada. Por ello, dado que la competencia afectada en el presente litigio, originariamente atribuida a Ceuta por su Estatuto, es más propia de una Comunidad Autónoma que no de un gobierno local, estimo que su defensa debe articularse, bien promoviendo un control indirecto o mediato de constitucionalidad de la norma legal supuestamente lesiva de la misma, solicitando al órgano jurisdiccional competente el planteamiento de la oportuna cuestión de inconstitucionalidad, en el curso del juicio de legalidad de que conoce, de resultas de la impugnación de un acto o disposición dictados en aplicación de la ley de referencia; bien, directamente, realizando, como ya se ha propuesto, una interpretación extensiva del art. 32.2 LOTC, en orden a facultar a la Asamblea y al Consejo de Gobierno de Ceuta y Melilla para que puedan plantear, si así lo acuerdan, un recurso de inconstitucionalidad contra la norma legal en cuestión. Además, tampoco creo que deba excluirse la posibilidad de que tales Ciudades Autónomas puedan ver reconocida la facultad de interponer un conflicto de competencia, el cual podría dar lugar, mediatamente, a un examen de la norma legal originaria de la controversia.

En cualquier caso, de lo que se trata es de normalizar las posibilidades de acceso de ambas Ciudades Autónomas al Tribunal Constitucional, en tanto que entes territoriales integrados, a través de sus Estatutos de Autonomía, siquiera sea peculiarmente, en la estructura compuesta del Estado. De ahí que se promueva su equiparación a las Comunidades Autónomas, al menos en las ocasiones en que aspiren a recabar la tutela constitucional de aquellas dimensiones de su autogobierno que sus Estatutos les reconocen, haciéndoles trascender a la mera condición de gobiernos locales. 


\section{EL PARÁMETRO DE CONTROL EN EL CONFLICTO EN DEFENSA DE LA AUTONOMÍA LOCAL}

Una vez reconocida la legitimación activa que asiste a las Ciudades Autónomas de Ceuta y Melilla para acceder a la jurisdicción constitucional, a través del conflicto en defensa de la autonomía local, el supremo intérprete de la Constitución se ve obligado a colmar una ostensible laguna que afecta a la regulación del procedimiento en cuestión. Dicha omisión se refiere al canon de validez que ha de utilizar el propio Tribunal Constitucional para determinar si se ha producido, o no, afectación lesiva de la autonomía que la Norma Fundamental atribuye al demandante. Así, inicialmente, la Sentencia recuerda, en su FJ $8 .^{\circ}$, que la Ley $7 / 1999$ «no contiene ningún precepto relativo al parámetro de control que debe aplicarse en los conflictos en defensa de la autonomía local, aun cuando el correspondiente canon o criterio valorativo puede ser deducido de la doctrina jurisprudencial contenida en las resoluciones en las que este Tribunal ha abordado el alcance de la garantía que la Constitución otorga a la autonomía municipal y provincial (arts. 137, 140, 141 y 142 CE)».

Dicha doctrina insiste en que el constituyente no predeterminó el contenido concreto de la autonomía local, sino que se limitó a establecer una garantía institucional de los elementos esenciales o del núcleo primario del autogobierno de los entes territoriales locales, correspondiendo así al legislador ejercer, a tal fin, su libertad inicial de configuración, respetando ese contenido mínimo (STC 159/2001, FJ 4. ${ }^{\circ}$ ). Dicho núcleo esencial se concreta «en el derecho de la comunidad local a participar, a través de órganos propios, en el gobierno y administración de cuantos asuntos le atañen, graduándose la intensidad de esa participación en función de la relación existente entre los intereses locales y supralocales dentro de tales asuntos o materias» De ahí que "para el ejercicio de esa participación en el gobierno y administración en cuanto les atañe, los órganos representativos de la comunidad local han de estar dotados de las potestades sin las que ninguna actuación autonómica es posible" (SSTC 32/1981 y 40/1998).

Pues bien, dicho legislador, de acuerdo con lo dispuesto en la jurisprudencia constitucional, sobre todo a partir de la STC 84/1982, no ha venido siendo otro que, fundamentalmente, el estatal, el cual, en virtud de la conexión establecida entre la garantía institucional de la autonomía local (art. $137 \mathrm{CE}$ ) y la competencia que ostenta el Estado para fijar "las bases del régimen jurídico de las Administraciones Públicas" (art. 149.1.18. $\left.{ }^{\circ} \mathrm{CE}\right)$, ha sido quien, "con carácter general y para todo tipo de materias, se ha encargado de fijar unos principios o bases relativos a 
los aspectos institucionales (organizativos y funcionales) y las competencias locales...". Tal doctrina, hoy, en parte, cuestionada ${ }^{9}$, ha inspirado el sistema que articula la Ley Reguladora de las Bases de Régimen Local, facultando así al Estado para esgrimir ese título competencial tranversal, a fin de condicionar y limitar, notablemente, a través de su intensa acción normativa, tanto el margen de autodeterminación que ha de corresponder al legislador autonómico, ex art. 148.1.2. ${ }^{\circ} \mathrm{CE}$, como la virtualidad misma del principio de autoorganización local. Ello le ha permitido, en la práctica, erigirse en guardián, al tiempo que en verdadero arquitecto, del modelo constitucional de autogobierno local, monopolizando, de facto, dicha tarea, en detrimento de quienes, de acuerdo con la Constitución, y la propia lógica político-territorial, sería, quizá, más consecuente que la protagonizaran, es decir, las Comunidades Autónomas ${ }^{10}$.

En cualquier caso, la atribución reiterada a dicha Ley de una específica y cualificada función en el ordenamiento, la cual no es otra que la de establecer el marco o estatuto jurídico básico del autogobierno local, desarrollando así las escuetas previsiones constitucionales sobre la materia, ha motivado que se haya considerado a la misma integrada en el Ilamado "bloque de la constitucionalidad" (SSTC 27/1987, 214/1989, 109/1998, 11/1999, 159/2001), empleándola como parámetro de enjuiciamiento de la ulterior actuación legislativa, de carácter sectorial, tanto estatal como autonómica, al efecto emanada. Tan notables cualidades que de ella se han venido predicando, se hacían derivar, de acuerdo con lo afirmado en su Exposición de Motivos, del hecho de tratarse de una norma que, con independencia de su rango, atañe a la construcción misma del Estado y al diseño de uno de los ordenamientos jurídicos que en él se integran. De ahí que se la haya estimado idónea para operar como norma interpuesta, a través de la cual cabe efectuar un control indirecto de la validez de las normas con rango de ley que posteriormente se elaboren, en materia de régimen local, a pesar de poseer, como éstas, igual rango jerárquico ${ }^{11}$.

${ }^{9}$ Entre otros, vid., F. CAAmaño Domínguez, "Autonomía local y Constitución. Razones para recuperar la causalidad perdida", en "Anuario del Gobierno Local 2003", Barcelona, Fundación Democracia y Gobierno Local, 2004, pp. 47-69; en especial, pp. 53 y ss.

10 J. M. a Porras Ramírez, "El autogobierno local en el Estado autonómico. Premisas para una reforma necesaria", en Revista Española de Derecho Constitucional, n. ${ }^{\circ} 75,2005$, pp. 211-237.; en especial, p. 216 y ss.

11 L. Morell Ocaña, "El régimen local español», Madrid, Civitas, 1988, pp. 39-40;

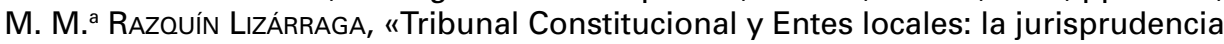
constitucional sobre régimen local», en Revista de Administración Pública, n. ${ }^{\circ} 122$, 
Dicha tesis, sostenida de modo continuado a lo largo del tiempo, ha sido considerablemente matizada por el propio Tribunal Constitucional, al dictar la resolución que es objeto del presente comentario, hasta el punto de llegar a constituir ésta, probablemente, la principal aportación de índole dogmática efectuada por el mismo por medio de su Sentencia. Semejante cambio de criterio aparece enunciado en su relevante Fundamento Jurídico Octavo. En él se indica que "los pronunciamientos efectuados, sin embargo, no permiten extraer conclusiones definitivas sobre el valor de la Ley de Bases de Régimen Local como canon de enjuiciamiento $y$, en todo caso, no son trasladables al conflicto en defensa de la autonomía local». No en vano, como el Tribunal reconoce, los mismos recayeron en procesos de declaración de inconstitucionalidad en los cuales se enjuiciaba la conformidad o disconformidad con la Constitución, por motivos competenciales, de leyes autonómicas o de la propia Ley de Bases de Régimen Local. En tales ocasiones, el Tribunal acudía a la noción de "bloque de la constitucionalidad" (art. 28.1 LOTC) para decidir si una concreta disposición se adecuaba o no al orden constitucional de distribución de competencias en materia de "régimen local», entendido como "régimen jurídico de las Administraciones Locales" (art. 149.1.18. ${ }^{\circ} \mathrm{CE}$ ), lo cual, en modo alguno, equivale, como ya manifestara la STC 11/1999, FJ 2. ${ }^{\circ}$, a "autonomía local» (art. $137 \mathrm{CE})$.

En consecuencia, el Tribunal Constitucional viene a reconocer que dicha Ley no constituye siempre canon de validez de aquellas leyes, estatales o autonómicas, que desarrollen aspectos concretos de la autonomía local. Sólo lo será, en todo caso, a efectos de contribuir a dilucidar cuestiones referidas al reparto competencial entre el Estado y las Comunidades Autónomas en relación con esa materia; más no a la hora de enjuiciar, desde una perspectiva sustantiva, normas, ya estatales, ya autonómicas, que desarrollen manifestaciones específicas de la autonomía local constitucionalmente garantizada. Por tanto, dicha Ley de Bases "no ocupa en nuestro ordenamiento una posición distinta a las demás leyes ordinarias del Estado, que pueden, por tanto, establecer disposiciones contrarias a la Ley de Bases de Régimen Local, las cuales deberán ser consideradas modificaciones legislativas pero no leyes inconstitucionales". De ahí que, en todo caso, dicha Ley sólo pueda emplearse, eventualmente, como canon de validez de la ley autonómi-

1990, pp. 259 y ss. J. M. BANDRÉS SÁNCHEZ-CRUZAT, "La autonomía local en la jurisprudencia del Tribunal Constitucional», en VVAA, "La autonomía local. Análisis jurisprudencial», Madrid, Marcial Pons, 1998, pp. 15-45; F. SosA WAGNER, "Manual de Derecho Local», Pamplona, Aranzadi, 2005, pp. 43 y ss.. 
ca, reiterando así lo indicado en el FJ $4 .^{\circ}$ de la STC 159/2001, en referencia a aquellas regulaciones que contiene, las cuales vienen a exteriorizar o manifestar el contenido de la autonomía local constitucionalmente garantizada, enraizándose así, de forma directa, en los arts. 137, 140 y $141 \mathrm{CE}$. Sin embargo, no tendrán esa utilidad aquellos otros preceptos que la misma alberga, que son mayoría, los cuales poseen una naturaleza bien distinta, no refiriéndose a la garantía institucional de la autonomía local, sino, más bien, al régimen jurídico de las Administraciones Locales, incardinándose, por tanto, en el art. 149.1.18. ${ }^{\circ} \mathrm{CE}$.

Con este cambio de orientación, prefigurado en alguna de sus Sentencias, como la ya citada STC 11/1999, el Tribunal Constitucional deja, por fin, de considerar al legislador básico estatal garante exclusivo de la autonomía local, frente a las potenciales agresiones o injerencias que pueda protagonizar, fundamentalmente, el legislador autonómico. No en vano, la consideración que venía el mismo exponiendo acerca de la función a aquél reservada, mostraba una comprensión disminuida de la autonomía local, como si ésta aún requiriera de la tutela del Estado para hacerse efectiva, tal que en tiempos ya pasados, al presuponerse que la misma no podía desarrollarse si no era con la previa habilitación positiva, expresa y tasada, que dicha ley debía hacer, con carácter general, de sus atribuciones competenciales. Se olvidaba así, intencionadamente, que los gobiernos locales actúan, dada su naturaleza política, directamente ordenados a la Constitución, de la que traen causa inmediata, además de en el marco de la ley, de la que, sin embargo, no derivan su existencia. De ahí que posean un derecho constitucional irrefrenable, bien es cierto que de configuración legal, a intervenir en cuantos asuntos afecten directamente al círculo de sus intereses (art. $137 \mathrm{CE})^{12}$.

Por todo ello, el canon que el Tribunal Constitucional deberá aplicar, en lo sucesivo, para resolver los conflictos en defensa de la autonomía local, promovidos frente a leyes estatales, vendrá representado por los preceptos constitucionales (arts. 137, 140 y $141 \mathrm{CE}$ ) que establecen la garantía institucional de la autonomía local, definiendo su contenido mínimo o esencial, el núcleo primario del autogobierno de los entes territoriales locales indisponible para el legislador, ya tenga éste, o no, la consideración de básico. En este sentido, no está de más recordar que el Tribunal Constitucional ha deducido una serie de principios que con-

12 J. L. CARro Fernández-VAlmayor, "La cláusula general de competencia municipal», en Anuario del Gobierno Local 1999-2000", Madrid, Marcial Pons, 2000, pp. 37-60; en especial, pp. 51 y ss. 
tribuyen a perfeccionar el aseguramiento y tutela más eficaces de la autonomía local. De ahí que el mismo aluda, cada vez más frecuentemente, a imitación de su homólogo federal alemán ${ }^{13}$, a la conveniencia de proyectar sobre el legislador sectorial, controles de subsidiariedad, proporcionalidad, necesidad, interdicción de la arbitrariedad, prevalencia de la voluntad local, eficacia en la gestión y naturaleza o condición de la actividad pública de referencia (SSTC 227/1988 y 11/1999), a fin de determinar la comisión por parte del mismo de excesos que puedan afectar a la identidad o cualidad propias del ámbito de actuación autónoma reconocido a los gobiernos locales. Tales criterios revelan su operatividad a la hora de oponerse a eventuales desapoderamientos competenciales, al traducirse en una exigencia de actuación leal, proporcional, no arbitraria y justificada del legislador al respecto.

No obstante, junto con los preceptos constitucionales, es claro que el Tribunal Constitucional ha de tener bien presente, igualmente, en la resolución de los conflictos en defensa de la autonomía local que se susciten, lo dispuesto singularmente en los Estatutos de Autonomía. Así, en atención al caso presente, el entendimiento de que Ceuta no es sino un ente local, lleva al Tribunal a considerar que las competencias que le reconoce su norma institucional básica, actualizando el contenido de su autonomía local constitucionalmente garantizada, no pueden más que tener esa naturaleza, viniendo así a constituir manifestaciones o exteriorizaciones de la misma. Por eso, reputa a esas normas contenidas en dicho Estatuto susceptibles de emplearse como parámetro de control de la ley estatal impugnada.

Más allá de este supuesto concreto, teniendo bien presentes los límites que la Constitución impone, los nuevos Estatutos de Cataluña y Andalucía han reforzado considerablemente la posición de las entidades locales. Así los mismos han incorporado un listado de competencias, asignadas a aquéllas, en relación con materias, siquiera sea parcialmente de titularidad autonómica, en las que se hacen presentes los intereses locales. Ello ha permitido acometer su definición más segura, prescindiendo del habitual e incierto recurso a cláusulas generales e indeterminadas. De ese modo se consigue introducir una cualificada garantía de sus estatus frente a la acción del legislador sectorial, tanto estatal como, sobre todo, autonómico, tentado habitualmente de eludir o menoscabar sus competencias. A ese fin, lo que se ha hecho

${ }^{13} \mathrm{~F}$. SCHOCH, «En relación a la situación de la autonomía local tras la Sentencia Rastede del Tribunal Constitucional Federal», en Documentación Administrativa, n. ${ }^{\circ} 234,1993$, pp. 281-321. 
en tales Estatutos, en el marco del sistema de distribución territorial del poder dispuesto en la Constitución, ha sido tomar como referencia la acotación realizada por el legislador estatal general de un núcleo mínimo y común de servicios obligatorios a desarrollar por los ayuntamientos y demás entidades locales consideradas básicas, de ámbito supramunicipal, determinando así los contenidos esenciales sobre los que han de recaer sus competencias. Desde esa perspectiva, dado el cometido habilitador y delimitador que Ilevan a cabo los Estatutos de Autonomía, tales normas se erigen en incuestionables parámetros de enjuiciamiento de las leyes sectoriales que incidan en el ámbito de autogobierno que se reconoce a los entes locales radicados en sus territorios $^{14}$.

\section{LA PROPORCIONALIDAD DE LA INTERVENCIÓN LEGISLATIVA DEL ESTADO EN EL ÁMBITO COMPETENCIAL DE LAS CIUDADES AUTÓNOMAS}

Finalmente, la Sentencia aborda la cuestión objeto propiamente de la demanda, esto es, la que insta a determinar si la modificación efectuada en la Disposición Adicional Tercera de la Ley 6/1998, de 13 de abril, de régimen del suelo y valoraciones, por el art. 68 de la Ley $55 / 1999$, de 29 de diciembre, de medidas fiscales, administrativas y de orden social, vulnera, o no, la autonomía de que goza el sujeto recurrente. Dicha reforma legislativa faculta al Estado, con respecto a Ceuta y Melilla, tanto a asumir la aprobación definitiva del Plan General de Ordenación Urbana que elaboren, y de sus revisiones o modificaciones; como, además, a aportar su informe preceptivo y vinculante con anterioridad a la aprobación de los Planes Parciales, y de sus modificaciones o revisiones.

Una medida tal es claro que afecta necesariamente a las posibilidades de ejercicio de la competencia que, en materia de "ordenación del territorio, urbanismo y vivienda" poseen ambas Ciudades Autónomas,

14 T. FONT I LLOVET, «El gobierno local en la reforma del Estado de las autonomías", en Anuario del Gobierno Local 2004, Barcelona, Fundación Democracia y Gobierno Local, 2005, pp. 13-36; en especial, pp. 35-36; y J. M. a PoRRAS RAMíREZ, «El autogobierno local en el Estado autonómico. Premisas para una reforma necesaria", op. cit., pp. 224-225; y, también, más en concreto, en relación con lo dispuesto novedosamente en los Estatutos valenciano, catalán y andaluz, cfr., J. M. ${ }^{a}$ PorRAS RAMíREZ, "El régimen local», en F. BALAGUeR CALLEJÓN (coord.), "Reformas estatutarias y distribución de competencias en el marco de la Unión Europea", Sevilla, Instituto Andaluz de Administración Pública, 2006, en prensa. 
en virtud de lo dispuesto en su correspondiente Estatuto de Autonomía (art. 21.1.1. a); materia en relación con la cual dicha competencia "comprenderá las facultades de administración, inspección y sanción, y, en los términos de la legislación del Estado, el ejercicio de la potestad normativa reglamentaria" (art. 21.2 EAC). En cualquier caso, la competencia afectada por la ley estatal de referencia deriva de una expresa atribución estatutaria, que excede el mero interés local (art. $25.2 \mathrm{~d}$ ) LRBRL), encuadrándose, más bien, entre aquéllas que poseen una naturaleza genuinamente autonómica (art. 148.1.3. ${ }^{\circ} \mathrm{CE}$ ).

El ejercicio reiterado de la misma por parte de la Ciudad Autónoma, hasta el momento de producirse su desapoderamiento parcial, como consecuencia de la intervención legislativa del Estado, revela la voluntad de Ceuta de hacer un uso exclusivo de la misma, en consonancia con lo dispuesto en la STC 61/1997 para todas las Comunidades Autónomas que disfrutan de dicha competencia. De ahí que, por medio de su demanda, solicitara la aplicación extensiva, en beneficio propio, de la jurisprudencia constitucional referida al reparto de competencias, entre el Estado y las Comunidades Autónomas, en materia de urbanismo, a sabiendas de que la misma excluye, en principio, al Estado de su ordenación básica, sin perjuicio de que el mismo pueda alegar otros títulos competenciales horizontales que permitan su intervención excepcional.

Sin embargo, el Tribunal Constitucional descarta esa pretensión al señalar que, "dado que Ceuta...no constituye una Comunidad Autónoma, no posee potestad legislativa; $y$ dado que su territorio no está integrado en una Comunidad Autónoma, que sería la instancia competente para dictar la legislación urbanística, debe concluirse que esa competencia legislativa en materia de urbanismo de la ciudad de Ceuta sólo puede corresponder al Estado" (FJ 11.\%). Así lo establece la Disposición Adicional Tercera de la Ley 6/1998, de 13 de abril, de régimen del suelo y valoraciones, la cual dispone: "Las ciudades de Ceuta y Melilla ejercerán las potestades normativas reglamentarias que tienen atribuidas por las Leyes Orgánicas 1/1995 y 2/1995, de 13 de marzo, dentro del marco de la presente Ley y de las que el Estado promulgue al efecto". Es, pues, la singularidad del régimen jurídico propio de esta Ciudad lo que explica que el ejercicio, por parte de la misma, de su competencia en materia de urbanismo, haya de producirse, a diferencia de lo que sucede con las Comunidades Autónomas, "en los términos de la legislación del Estado", razón por la cual éste se encuentra plenamente habilitado para determinar el mayor o menor margen de actuación normativa con que podrá contar la Ciudad Autónoma. 
Aún así, la Sentencia reconoce que la libertad de configuración que el legislador estatal posee, a este respecto, no es plena, ya que el mismo habrá de respetar, en todo caso, un núcleo mínimo identificable de facultades, competencias y atribuciones, al menos en el plano de la ejecución o gestión urbanística, que Ceuta podrá ejercer, de forma ineludible, en su condición, cuando menos, de ente local. De lo contrario, desvirtuaría la imagen socialmente reconocible de lo que es un ente territorial de esa naturaleza. No en vano, el urbanismo constituye, indiscutiblemente, tal y como manifiesta el art. 25.2 d) LRBRL, un asunto de interés municipal, que origina un conjunto de competencias las cuales implican el ejercicio de potestades inherentes a la autonomía local. Así, tras afirmar la competencia del Estado para legislar sobre el planeamiento urbanístico en el territorio de Ceuta, el Tribunal examina los preceptos legales impugnados, a efectos de determinar si los mismos vulneran, o no, la autonomía local constitucionalmente garantizada a la Ciudad Autónoma. De ese modo, proyecta un control de proporcionalidad acerca de la amplitud de la intervención realizada y de la importancia de los intereses que se pretenden salvaguardar mediante la misma.

De este modo, viene a constatar, en primer lugar, como se ha indicado, que el legislador competente para dictar la normativa urbanística, el cual no es otro que el estatal, ha de respetar un núcleo mínimo identificable de competencias que hagan reconocibles a los entes locales como instancias decisorias autónomas. En relación con el urbanismo, el Tribunal Constitucional declara, aplicando su jurisprudencia ya consolidada, expuesta, de forma paradigmática, en su STC 159/2001, que la aprobación definitiva de los planes generales no forma parte de ese núcleo esencial, "ya que la autonomía local sólo obliga a que existan competencias municipales relevantes y reconocibles en la ordenación y el planeamiento urbanístico, como las que se ejercen en las fases de aprobación inicial y provisional» (FJ 12. ${ }^{\circ}$. En consecuencia, dado que en el precepto legal impugnado el legislador se limita a atribuir al Ministerio de Fomento la aprobación definitiva del plan general de ordenación urbana, así como sus modificaciones y revisiones, al igual que hacen las leyes territoriales en la materia a los órganos autonómicos correspondientes, en modo alguno se está privando a Ceuta de intervenir en el proceso de planificación, al seguir correspondiéndole a dicha Ciudad la tramitación y elaboración previa a la aprobación definitiva de dichos planes, y de sus modificaciones o revisiones.

Dicha intervención legislativa favorable al Ministerio de Fomento no supone, tampoco, una vulneración del Estatuto de Autonomía de la Ciudad Autónoma, ya que el ejercicio de las facultades de administra- 
ción, inspección y sanción, además de la potestad normativa reglamentaria que ésta tiene atribuida sobre la materia (art. 21.1.1. ${ }^{\circ} \mathrm{EAC}$ ) han de producirse "en los términos que establezca la legislación general del Estado" (art. 21.1 EAC). Razón por la que, dado que la ley estatal no suprime dicha potestad, sino que, en todo caso, viene, tan sólo, a constreñirla, cabe afirmar que no se ha afectado al contenido propio del Estatuto, modificando tácitamente uno de sus preceptos, sin seguir el procedimiento que se establece en su art. 41, tal y como sugiere el demandante. El más reducido margen de actuación normativa que se deja, en la práctica, al titular de esa potestad reglamentaria no es sino el resultado de una actuación legislativa legítima, en tanto que contemplada en el propio Estatuto, que respeta la autonomía local constitucionalmente garantizada en su consideración más básica.

Por otra parte, la atribución legislativa al Ministerio de Fomento de la competencia que le lleva a emitir informe preceptivo y vinculante, con carácter previo a la aprobación definitiva de los planes parciales urbanísticos, y de sus modificaciones o revisiones, tampoco supone una afectación exorbitante, por lo desproporcionada, en la esfera de intereses locales, ya que el legislador estatal ha garantizado a los órganos competentes de la ciudad de Ceuta su participación en la elaboración, redacción, aprobación inicial y provisional de los planes parciales de la ciudad, y de sus modificaciones o revisiones, así como su aprobación definitiva. De ahí que pueda considerarse que aquélla posee un mínimo de competencias que le permiten ser reconocida como una instancia con capacidad para decidir autónomamente, sobre un asunto de su interés, como es el urbanismo. Es así que los condicionamientos y restricciones que el ente territorial local ha de sufrir encuentran justificación, según ya determinaba la STC 51/2004, FJ $12 .^{\circ}$, cuando concurren, como es el caso, intereses de carácter supramunicipal y controles de legalidad, los cuales han de ser apreciados, de acuerdo con lo dispuesto en el bloque de la constitucionalidad, por la Administración supraordenada correspondiente, la cual, en esta ocasión, no es otra, que la estatal. Ésta será, por tanto, quien excepcionalmente, a juicio del Tribunal Constitucional, al no constituir Ceuta una Comunidad Autónoma, ni encontrarse ubicado su territorio en ninguna de las actualmente existentes, haya de ejercer en esa ciudad las competencias urbanísticas que, en la generalidad del territorio nacional, corresponden a las Comunidades Autónomas.

Así pues, en resumen, el Tribunal Constitucional concluye afirmando que "la actividad de planeamiento derivado de la ciudad de Ceuta afecta claramente a intereses de carácter inequívocamente supramunicipal, cuya gestión constituye el objeto de competencias del Estado, 
lo cual justifica sobradamente la intervención estatal en la ordenación urbanística de ese territorio municipal con la intensidad que prevé el precepto impugnado" (FJ 13. ${ }^{\circ}$. No existe, en consecuencia, vulneración alguna de la autonomía local garantizada constitucionalmente a dicha ciudad, sino ejercicio proporcional de las competencias del Estado sobre la materia de referencia. Otra cosa bien distinta es que, con ese proceder restrictivo, el legislador esté impidiendo a la Ciudad Autónoma recurrente desarrollar todas las potencialidades de su autogobierno sobre la materia de referencia. La asimetría que así se genera introduce una desarmonía en la configuración del Estado autonómico, que sólo cabe paliar promoviendo una reforma estatutaria que permita la plena equiparación de Ceuta y Melilla con las Comunidades Autónomas. Mas, que esto ocurra, escapa a su sola voluntad, incumbiendo a aquéllos que han asumido la responsabilidad de construir un modelo territorial de Estado más coherente y armónico.

\section{VALORACIÓN FINAL}

La resolución, por primera vez mediante sentencia, de un conflicto en defensa de la autonomía local, representa una gran oportunidad para colmar las dudas aplicativas que suscita un procedimiento constitucional en el que abundan los defectos y omisiones en su regulación. Aún así, la Sentencia de referencia posee un carácter extraordinario en lo que se refiere a la resolución de este tipo de conflictos, ya que el promotor de la demanda no es un gobierno local al uso, sino la Ciudad Autónoma de Ceuta, forzada a ello al haber inadmitido el Tribunal Constitucional, "por falta de legitimación", el recurso de inconstitucionalidad promovido por la misma contra una ley estatal que, a su juicio, vulnera su autonomía constitucionalmente garantizada. Así, en la Sentencia de referencia se discuten tres cuestiones fundamentales que conviene destacar.

En primer lugar, la misma alude a la legitimación subjetiva para interponer un conflicto en defensa de la autonomía local. El Tribunal Constitucional viene así a determinar, con carácter general, que es ésta la única vía a través de la cual las Ciudades Autónomas de Ceuta y Melilla pueden acceder directamente a la jurisdicción constitucional, en defensa, frente a leyes, de su autonomía garantizada, tanto por la Constitución, como por sus respectivos Estatutos. Dicho entendimiento devalúa la posición que ocupan las Ciudades Autónomas en la organización territorial del Estado, la cual deriva de su Estatuto, afectando negativamente al funcionamiento, equilibrado y armónico, del Estado 
autonómico, necesitado de una interpretación integradora, "tendente a la simetría", de los principales rasgos diferenciadores que asisten a los entes territoriales que lo componen, en aras de así propiciar un desarrollo más cohesivo del mismo. De ahí que, frente a lo indicado por el Tribunal Constitucional, se proponga la equiparación de Ceuta y Melilla a las Comunidades Autónomas, en las ocasiones en que aquéllas aspiren a recabar la tutela constitucional de las facetas o dimensiones de su autogobierno, que sus Estatutos les reconocen, las cuales les hacen trascender, claramente, a la mera condición de gobiernos locales.

En consecuencia, dado que el peculiar régimen competencial que poseen Ceuta y Melilla no está amparado, íntegramente, a través del procedimiento constitucional de referencia, en lo que aquél excede de la autonomía local constitucional garantizada, como evidencia la naturaleza de la competencia afectada en el presente litigio, más propia de una Comunidad Autónoma que un ente local, más razonable sería articular su defensa directa frente a la acción del legislador realizando una interpretación extensiva del art. 32.2 LOTC, en orden a facultar a la Asamblea y al Consejo de Gobierno de tales Ciudades Autónomas para que puedan plantear, si así lo acuerdan, un recurso de inconstitucionalidad contra la norma legal en cuestión. Con ello no se pretende sino normalizar las posibilidades de acceso de Ceuta y Melilla al Tribunal Constitucional, en tanto que entes territoriales integrados, a través de sus Estatutos de Autonomía, en la estructura compuesta del Estado.

En segundo lugar, el Tribunal Constitucional fija, ante la omisión del legislador, el parámetro de control a emplear por el Tribunal Constitucional, colmando así una ostensible laguna que afecta a la regulación del procedimiento en cuestión. A este respecto, descarta al legislador básico estatal como garante exclusivo de la autonomía local, indicando así que la Ley de Bases de Régimen Local no ocupa en nuestro ordenamiento una posición distinta a las demás leyes ordinarias del Estado. Por todo ello, el canon que el Tribunal Constitucional aplicará, en lo sucesivo, para resolver los conflictos en defensa de la autonomía local, promovidos frente a leyes estatales, vendrá representado por los preceptos constitucionales (art. 137, 140, 141 y 142 CE), que establecen el contenido mínimo o esencial, el núcleo primario del autogobierno de los entes territoriales locales, indisponible para el legislador, ya tenga éste, o no, la consideración de básico. A su vez, el Tribunal Constitucional admite que habrá de tener bien presente, a esos efectos, también, lo dispuesto singularmente en los Estatutos de Autonomía, ya que los mismos, en ocasiones, actualizan el contenido de la autonomía local constitucionalmente garantizada, reconociendo competencias que no son sino manifestaciones o exteriorizaciones de la misma. Desde esta 
perspectiva, dado el cometido habilitador y delimitador que llevan a cabo, los Estatutos se erigen en incuestionables parámetros de enjuiciamiento de las leyes sectoriales que inciden en el ámbito de autogobierno que se reconoce a los entes locales radicados en sus territorios.

$Y$, en tercer lugar, viene a juzgarse la proporcionalidad de la actuación legislativa del Estado, valorándose si se ha producido, o no, menoscabo alguno de la autonomía local constitucionalmente garantizada. Dado que la competencia que, en materia de urbanismo, posee la ciudad de Ceuta ha de ejercerse, de acuerdo con su Estatuto, "en los términos de la legislación del Estado", queda claro que éste se considera plenamente habilitado para determinar el mayor o menor margen de actuación normativa con que podrá contar la Ciudad Autónoma. EI único límite que se interpone a su intervención es aquél que le prohíbe, de acuerdo con la Constitución, incidir negativamente en el núcleo mínimo identificable de competencias que Ceuta ha de retener, en tanto que ente local, en la ordenación de la materia. Como ese núcleo esencial no aparece afectado, no existe vulneración de la autonomía local constitucionalmente garantizada. Pero lo que sí se aborta con intervenciones legislativas como la presente, y esto es algo que la Sentencia no entra lógicamente a valorar, al escapar a su cometido, es la posibilidad de que las Ciudades Autónomas puedan constituir un ordenamiento autonómico propio, desarrollando una capacidad normativa, materialmente legislativa, en ámbitos que son objeto de su competencia estatutaria. Las disfunciones que con ese impedimento se generan no deben subestimarse. Por eso, quizá, sólo si se apela a una reforma estatutaria que consiga equiparar a Ceuta y Melilla a las Comunidades Autónomas que gozan de una plena garantía constitucional de su autogobierno, pueda solucionarse una anomalía estructural en el funcionamiento de nuestro modelo de Estado que, con el tiempo, tal y como esta Sentencia viene a poner de manifiesto, se hace cada vez más notable.

\section{Resumen}

La primera sentencia resolutoria de un conflicto en defensa de la autonomía local aclara algunos extremos vinculados a la regulación de un procedimiento constitucional insuficientemente precisado por el legislador y, en consecuencia, sujeto a múltiples dudas interpretativas en orden a su correcta aplicación. Así, la misma determina, tan restrictiva como cuestionablemente, que la única vía con la que cuentan las Ciudades Autónomas de Ceuta y Melilla para acceder directamente a la jurisdicción constitucional, en defensa frente a leyes de sus competencias 
estatutarias, es la que proporciona este nuevo proceso. Ello devalúa su estatus constitucional, ya que no repara en la peculiar posición que, merced a sus Estatutos, ocupan ambas Ciudades Autónomas en la organización territorial del Estado. Así, la Sentencia considera que no son Comunidades Autónomas, a pesar de la significación que muestran muchas de las competencias que se les atribuyen, como es el caso de la que, en materia de urbanismo, es objeto de la presente demanda. A su vez, la Sentencia determina, colmando una notable laguna legislativa, cuál es el parámetro de control que habrá de emplear el Tribunal Constitucional, insistiendo en que no forma parte del mismo la Ley de Bases de Régimen Local, al aparecer únicamente compuesto por los preceptos constitucionales referidos a la garantía institucional de la autonomía local, y, en todo caso, además, por aquéllos que se incluyen en los Estatutos de Autonomía, atribuyendo competencias a sus órganos representativos. Finalmente, la Sentencia valora la proporcionalidad de la intervención legislativa del Estado en el ámbito competencial de la Ciudad Autónoma recurrente. Viene así a indicar que la misma no vulnera la autonomía local constitucionalmente garantizada, al encontrarse habilitada por el propio Estatuto de Autonomía y respetar un núcleo mínimo de competencias a las instituciones territoriales. Sin embargo, la Sentencia, al confirmar, en toda ocasión, esto es, con independencia del fallo, los impedimentos que, a su juicio, obstaculizan la plena equiparación de Ceuta y Melilla a la condición asimilada de Comunidades Autónomas, niega el desarrollo de las potencialidades de su autogobierno característico, no contribuyendo con ello a limar, por vía interpretativa, las asimetrías que impiden el desarrollo armónico de la forma territorial de Estado.

\title{
Palabras clave
}

Ciudades Autónomas, organización territorial del Estado, jurisdicción constitucional, conflicto en defensa de la autonomía local.

\section{Title}

"THE AUTONOMIC TOWNS OF CEUTA AND MELILLA AND THE CONFLICT TO DEFEND DE LOCAL SELF-GOVERNMENT COMPETENCES. (COMMENTARY TO THE SENTENCE 240/2006).

\begin{abstract}
The first sentence pronounced in accordance with the new process laid down specifically to defend the local self-government competences
\end{abstract}


contributes to clarify some of the numerous doubts they make difficult its interpretation and application. Therefore the resolution decides this is the only constitutional process that the Autonomic Towns of Ceuta and Melilla have to access directly to the constitutional Court requiring the protection of their competences allegedly affected by state laws. Such restrictive and questionable determination depreciates the constitutional status of Ceuta and Melilla in the context of the territorial organisation of the State. That is because the Sentence considers they are not exactly Autonomic Communities, despite the significance of many of the competences they have acknowledged by their respective Statute of Autonomy, as the one it gave rise to claim in this occasion. Also the Sentence determines which is the parameter that shall be use to control laws. It comprises the constitutional principles referred to the local self-government order and all those references included in the Statutes of Autonomy that conferred competences to the local authorities. Finally, the Sentence judges the proportion of the state legal intervention in the competence area reserved to the Autonomic Town of Ceuta, deciding that its action does not constitute an infraction of the Constitution while it has the authorization of the Statute of Autonomy. However this resolution keeps the impediments that stand in the way to put Ceuta and Melilla on a level with the Autonomic Communities. That provokes negative implications in the harmonic development of the territorial organisation of the State.

\section{Key words}

Autonomic Towns, territorial organisation of the State, constitutional Court, conflict to defend the local self-government competences. 